\section{Primary hyperoxaluria type 1}

A

2-month-old healthy thriving term male infant presented with hypocalcaemic generalised tonic-clonic seizures associated with renal failure (plasma creatinine level $198 \mu \mathrm{mol} / \mathrm{l}$ ), severe metabolic acidosis ( $\mathrm{pH} 6.94$ ) and pancytopenia. Renal ultrasound showed bilateral echogenic kidneys, unlike classical nephrocalcinosis with mild prominence of the pelvicalyceal systems (fig l).

Percutaneous renal biopsy showed widespread and marked tubular damage with associated interstitial fibrosis and massive deposition of crystalline material in the tubular lumina. The crystals had a characteristic fan-like appearance and were refractile in nature, suggestive of oxalate nephropathy (fig 2). Bone marrow aspirate showed scattered macrophages containing oxalate crystals throughout.

The above findings led to the diagnosis of primary hyperoxaluria. Fundoscopy showed small oxalate deposits throughout the retina (fig 3) and echocardiogram showed no significant myocardial deposits. Primary hyperoxaluria genetic screening showed that the patient was a compound heterozygote (heterozygous for both AGXT gene mutation 508G $\rightarrow$ A and c.466G $\rightarrow$ A (Glyl56Arg) in exon 4). His plasma oxalate level was $231 \mu \mathrm{mol} / \mathrm{l}$ (normal $<10)$ with urine oxalate:creatinine ratio of $685 \mu \mathrm{mol} / \mathrm{l}$ (normal 4-98). He started receiving haemodialysis, has had a successful living-related liver transplant and is awaiting a living-related kidney transplant.

Primary hyperoxaluria is an autosomal recessive disorder, causing overproduction of endogenous oxalic acid, ${ }^{1}$ leading to accumulation of oxalate in the body. Oxalate, the poorly soluble end product is normally excreted by the kidneys; however, in large quantities in primary hyperoxaluria, it cannot be fully excreted and so is deposited in many organs, including the eyes, skeleton and heart, but predominantly in the kidneys, leading to nephrocalcinosis, recurrent nephrolithiasis and eventually end-stage renal failure. ${ }^{23}$

In this case, the patient was diagnosed with type 1 infantile primary hyperoxaluria, the rarest type of primary hyperoxaluria, which has a poor prognosis requiring concurrent or sequential liver and renal transplantation as the mainstay of treatment. ${ }^{2-5}$

Michal J Ajzensztein, Neil J Sebire, Richard S Trompeter, Stephen D Marks Great Ormond Street Hospital for Children NHS Trust, London, UK

Correspondence to: Dr S Marks, Department of Paediatric Nephrology, Great Ormond Street Hospital for Children NHS Trust, Great Ormond Street, London WCIN 3JH, UK; markss2@gosh.nhs.uk

Competing interests: None declared.

We would like to acknowledge Mr Rajnish Sekhri and Mr Ken Nischal for their assistance and for providing figure 3.

\section{References}

1 Jones C, Mughal Z. Disorders of mineral metabolism and nephrolithiasis: primary hyperoxaluria type I. In: Webb N, Postlethwaite R, eds. Clinical paediatric nephrology 3rd edn. Oxford: Oxford Medical Publications, 2003:91-3.

2 Karel VAJ, Wolff ED. Hyperoxaluria and oxalosis. In: Chester M, Edelmann JR, eds. Paediatric kidney disease, 2nd edn. Boston: Little Brown \& Company, 1992:1687-93.

3 Cochat P, Collard LBDE. Primary hyperoxaluria. In: Avner ED, Harmon WE, Niaudet $\mathrm{P}$, eds. Pediatric nephrology. 5th edn. Section VI: tubular disease, Chapter 42, Philadelphia: Lippincott Williams \& Wilkins, 2003:807-16.

4 Danpure CJ. Molecular etiology of primary hyperoxaluria type 1: new directions for treatment. Am J Nephrol 2005;25:303-10.

5 Kemper MJ. Concurrent or sequential liver and kidney transplantation in children with primary hyperoxaluria type 1? Pediatr Transplant 2005;9:693-6. doi: $10.1136 /$ adc.2006.107334

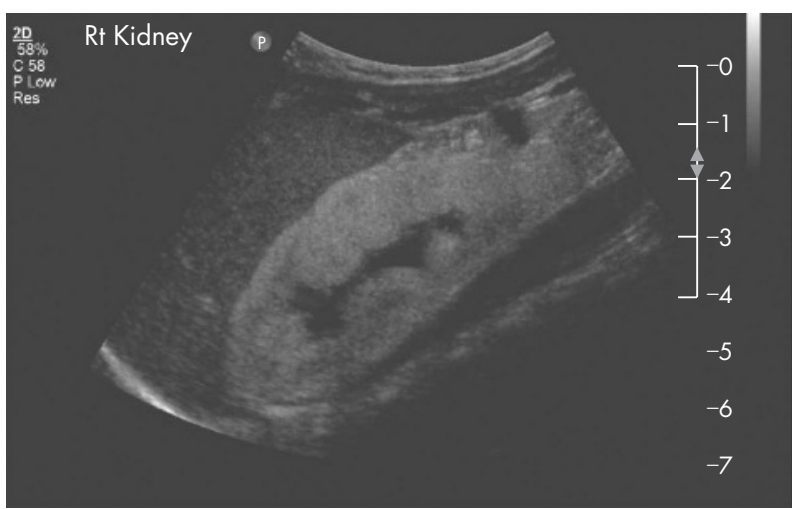

Figure 1 Renal ultrasound showed bilateral globally echogenic kidneys with some loss of corticomedullary differentiation and mild prominence of pelvicalyceal systems (the left and right kidneys measured 5.6 and $5.7 \mathrm{~cm}$, respectively, with the 50th centile for age of $5.5 \mathrm{~cm}$ ).

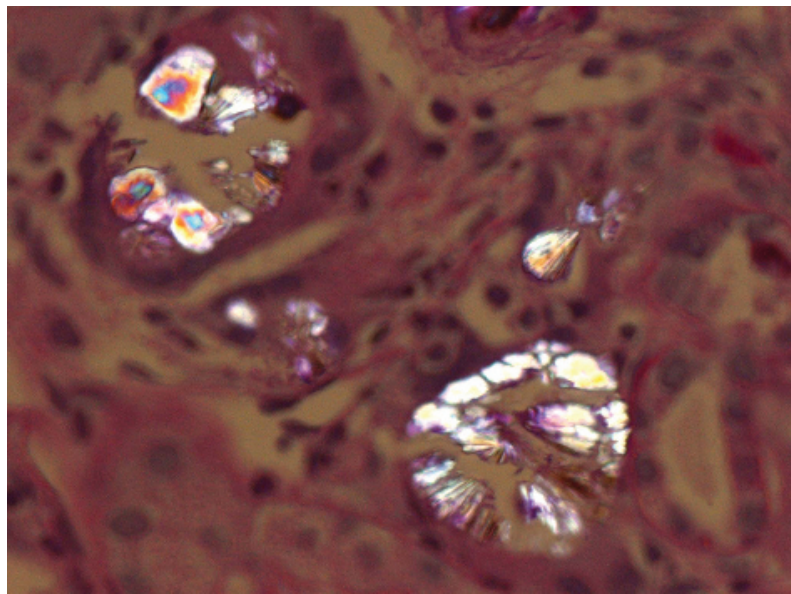

Figure 2 Histopathology of percutaneous renal biopsy (H\&E stain photographed with polarised light at original magnification $\times 250$ ) showing tubules containing crystalline oxalate deposits which are double refractile, showing the full spectrum of colours.

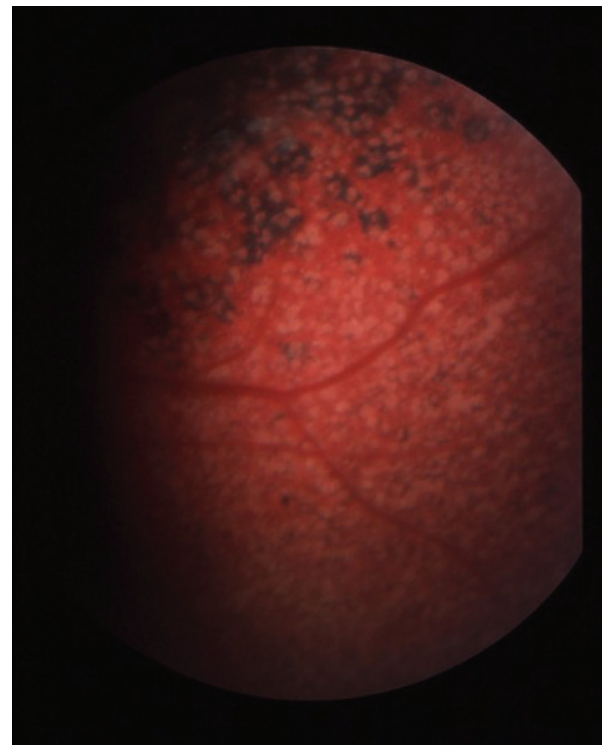

Figure 3 Fundoscopy of mid-peripheral retina showing areas of retinal pigment epithelial lacunae with areas of hypertrophy and no attenuation of vessels. 